\title{
Article \\ Processing Parameters and Ion Excipients Affect the Physicochemical Characteristics of the Stereocomplex-Formed Polylactide-b-Polyethylene Glycol Nanoparticles and Their Pharmacokinetics
}

\author{
Kohei Ogawa ${ }^{1,2}$, Hidemasa Katsumi ${ }^{2, *}$, Yasushi Moroto ${ }^{1}$, Masaki Morishita ${ }^{2}$ and Akira Yamamoto ${ }^{2}(\mathbb{D}$ \\ 1 Formulation R\&D Laboratory, CMC R\&D Division, Shionogi Co., Ltd., Amagasaki-shi 660-0813, Japan; \\ kohei.ogawa@shionogi.co.jp (K.O.); yasushi.moroto@shionogi.co.jp (Y.M.) \\ 2 Department of Biopharmaceutics, Kyoto Pharmaceutical University, Yamashina-ku, Kyoto 607-8414, Japan; \\ morishita@mb.kyoto-phu.ac.jp (M.M.); yamamoto@mb.kyoto-phu.ac.jp (A.Y.) \\ * Correspondence: hkatsumi@mb.kyoto-phu.ac.jp; Tel.: +81-75-595-4662; Fax: +81-75-595-4761
}

check for

updates

Citation: Ogawa, K.; Katsumi, H.;

Moroto, Y.; Morishita, M.; Yamamoto,

A. Processing Parameters and Ion Excipients Affect the Physicochemical Characteristics of the StereocomplexFormed Polylactide-b-Polyethylene Glycol Nanoparticles and Their Pharmacokinetics. Pharmaceutics 2022, 14, 568. https://doi.org/ $10.3390 /$ pharmaceutics 14030568

Academic Editor: Neal M. Davies

Received: 21 January 2022

Accepted: 2 March 2022

Published: 4 March 2022

Publisher's Note: MDPI stays neutral with regard to jurisdictional claims in published maps and institutional affiliations.

Copyright: (C) 2022 by the authors. Licensee MDPI, Basel, Switzerland. This article is an open access article distributed under the terms and conditions of the Creative Commons Attribution (CC BY) license (https:// creativecommons.org/licenses/by/ $4.0 /)$.

\begin{abstract}
To optimize the characteristics of stereocomplex polylactide-b-polyethylene glycol nanoparticles (SC-PEG NPs) in terms of pharmacokinetics (PK), we chose continuous anti-solvent precipitation with a T-junction as a preparation method and investigated the effect of using solvents containing an ion excipient (lithium bromide, $\mathrm{LiBr}$ ) on the characteristics of SC-PEG NPs by changing the processing temperature and total flow rate (TFR). Processing temperatures above the melting temperature $\left(\mathrm{T}_{\mathrm{m}}\right)$ of the PEG domain produced a sharper polydispersity and denser surface PEG densities of SC-PEG NPs than those produced by processing temperatures below the Tm of the PEG domains. Response surface analysis revealed that a higher $\mathrm{LiBr}$ concentration and slower TFR resulted in larger and denser hydrodynamic diameters $\left(D_{h}\right)$ and surface PEG densities, respectively. However, a high concentration $(300 \mathrm{mM})$ of $\mathrm{LiBr}$ resulted in a decreased drug loading content (DLC). ${ }^{14} \mathrm{C}$-tamoxifenloaded ${ }^{111}$ In-SC-PEG NPs with larger $D_{h}$ and denser surface PEG densities showed a prolonged plasma retention and low tissue distribution after intravenous injection in mice. These results indicate that the novel strategy of using solvents containing $\mathrm{LiBr}$ at different processing temperatures and TFR can broadly control characteristics of SC-PEG NPs, such as $\mathrm{D}_{\mathrm{h}}$, surface PEG densities, and DLC, which alter the PK profiles and tissue distributions.
\end{abstract}

Keywords: polymeric nanoparticle; anti-solvent precipitations; ion excipients; flow rate; process parameters; pharmacokinetics; characterization

\section{Introduction}

Polymeric nanoparticles (NPs) have been intensively developed worldwide for various purposes, especially the treatment of cancer [1-4]. Polymeric NPs have been chemically synthesized and modified to provide various physicochemical characteristics, such as hydrophilic-lipophilic balance, targeting moiety, size, and surface properties [5-7]. Due to the stealth properties of polyethylene glycol (PEG), polymeric NPs for passive targeting increase blood circulation time and accumulate in tumor tissues (i.e., enhanced permeability and retention effects) [8,9]. In addition, surface-modified, or grafted, NPs were investigated for active targeting or tissue engineering. $[10,11]$ Thus, polymeric NPs would be promising delivery systems.

Polylactide-b-polyethylene glycol (PLA-PEG) NPs are a promising polymeric NP delivery system. The PLA-PEG NPs are biodegradable and biocompatible. Some PLA-PEG NPs have been developed for the treatment of cancer and have progressed to clinical trials [3,4]. PLA-PEG NPs form via hydrophobic interaction of the PLA domain and are stabilized by the hydrophilic PEG domain. Hydrophobic drugs can be encapsulated in the PLA core and are subsequently released slowly. We recently performed orthogonal characterization 
studies to identify the relationship between the physicochemical properties of PLA-PEG NPs composed of different lactide isomers and to determine their pharmacokinetic (PK) profiles [12]. We also elucidated that stereocomplex PLA-PEG (SC-PEG) NPs composed of an equimolar mixture of L-lactide-based PLA-PEG (PLLA-PEG uni $_{1}$ ) and D-lactide-based


due to their core crystallinity and high surface PEG density.

The guidelines for polymeric NPs recommend the characterization of NPs to identify the critical quality attributes, data concerning the consistency from nonclinical studies to human use, and reproducibility in the manufacture of polymeric NPs $[13,14]$. However, few reports have investigated the manufacture or preparation process of polymeric NPs $[15,16]$ or have elucidated the relationship between the formulation attributes and PK profiles [17].

In the present study, we investigated the relationship between the process parameters of prepared NPs and their physicochemical properties in terms of PK. A continuous anti-solvent precipitation procedure with a T-junction was selected to prepare the SCPEG NPs. This procedure has been used to prepare NPs $[18,19]$ and is superior to the conventional bulk preparation method, such as the solvent evaporation method, in terms of scalability and reproducibility [20,21]. It was also reported that process parameters, such as temperature, flow rate, and flow rate ratio, affect the characteristics of NPs [21,22]. In addition, the conformations of macromolecules in a good solvent can be controlled by adding $\operatorname{LiBr}[23,24]$. However, the application of LiBr in the preparation of NPs has not been described. Accordingly, a good solvent containing LiBr is expected to be a novel strategy to control the characteristics of the prepared SC-PEG NPs.

We focused on the processing temperature, which was set based on the physicochemical properties of the PLA-PEG unimer, such as the melting temperature $\left(\mathrm{T}_{\mathrm{m}}\right)$ and total flow rate (TFR), and investigated the effects of a good solvent containing ion excipients, such as lithium bromide ( $\mathrm{LiBr})$, on the physicochemical properties of SC-PEG NPs. The effects of varying the processing parameters on the characteristics of SC-PEG NPs were determined by orthogonal procedures, such as proton nuclear magnetic resonance ( $\left.{ }^{1} \mathrm{H}-\mathrm{NMR}\right)$, size-exclusion chromatography-multiangle light scattering (SEC-MALS), and solid-phase extraction (SPE). Finally, PK studies were performed with SC-PEG NPs with different physicochemical properties, prepared using different processing parameters.

\section{Materials and Methods}

\subsection{Chemicals and Reagents}

Methoxy-polyethylene glycol (mPEG, 5kDa), deuterium chloroform, and deuterium oxide were purchased from Sigma Aldrich (St. Louis, MO, USA). L-lactide and tin (II) 2-ethylhexanoate $\left(\mathrm{Sn}(\mathrm{Oct})_{2}\right)$ were purchased from Tokyo Chemical Industry (Tokyo, Japan). D-lactide was purchased from Leap Labchem (Hangzhou, China). Tamoxifen-free base (TAM) was purchased from MP Biomedicals (Santa Ana, CA, USA). Dichloromethane (DCM), diethyl ether, toluene, dimethyl sulfoxide, and N, N-dimethyl formamide (DMF, HPLC grade) were purchased from Fujifilm Wako Chemical Industries (Tokyo, Japan). Acetonitrile (MeCN, HPLC grade) and LiBr were purchased from Kanto Chemicals (Tokyo, Japan). Soluene 350 was purchased from Perkin-Elmer (Waltham, MA, USA). Clear-Sol I was purchased from Nacalai Tesque (Boston, MA, USA). ${ }^{14} \mathrm{C}-\mathrm{TAM}$ [N-methyl- $\left.{ }^{14} \mathrm{C}\right]$ was purchased from American Radiolabeled Chemicals Inc. (St. Louis, MO, USA). ${ }^{111}$ Indium chloride ([ $\left.\left.{ }^{111} \mathrm{In}\right] \mathrm{InCl}_{3}\right)$ was supplied by Nihon Medi-Physics Co. (Tokyo, Japan). All other chemicals were obtained commercially as reagent-grade products.

\subsection{Animals}

Six-week-old male ddY mice were purchased from Japan SLC (Shizuoka, Japan). The animals were maintained under specific pathogen-free conditions. All animal experiments were conducted according to the principles and procedures outlined in the National Institutes of Health Guide for the Care and Use of Laboratory Animals. The Animal Ex- 
perimentation Committee of Kyoto Pharmaceutical University approved all experimental protocols involving animals.

\subsection{Synthesis of L-Lactide-Based PLA-PEG (PLLA-PEG $\left.{ }_{u n i}\right)$ and D-Lactide-Based PLA-PEG} $\left(P D L A-P E G_{u n i}\right)$

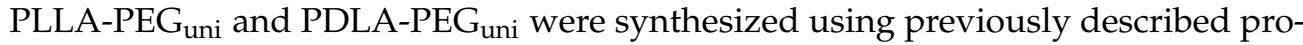
cedures [12]. Briefly, mPEG $5 \mathrm{kDa}$ was added to a round-bottom flask and vacuumed at $110^{\circ} \mathrm{C}$. L- or D-lactide was added to the flask for the synthesis. Sn $(\mathrm{Oct})_{2}$ was also added as a catalyst. The resultant mixture was allowed to react at $160{ }^{\circ} \mathrm{C}$ for $12 \mathrm{~h}$. The reactants were dissolved in DCM and then purified. Purified PLLA-PEG ${ }_{u n i}$ and PDLA-PEG ${ }_{u n i}$ were dried under vacuum.

\subsection{Characterizations of Synthesized PLLA-PEG $G_{u n i}$ and $P D L A-P E G_{u n i}$}

2.4.1. Number-Based Molecular Weight $\left(\mathrm{Mn}_{\mathrm{uni}}\right)$ and Polydispersity Index of Unimers $\left(\mathrm{PdI}_{\text {uni }}\right)$ Determinations

The $\mathrm{Mn}_{\text {uni }}$ of PLLA-PEG ${ }_{\text {uni }}$ and PDLA-PEG uni were evaluated by ${ }^{1} \mathrm{H}-\mathrm{NMR}$ spectroscopy (Figure $\mathrm{S1B}, \mathrm{C}$ ). The $\mathrm{Mn}_{\text {uni }}$ was determined as previously reported [25]. $\mathrm{PdI}_{\text {uni }}$ were determined by the previously reported size-exclusion chromatography (SEC)-refractive index (RI) [12]. Calibrated standard polyethylene oxide (Agilent, San Diego, CA, USA) was used for calibrating the retention time and molecular weight. The relative molecular weight was calculated using $\mu 7$ plus (System Instruments, Kanagawa, Japan).

\subsubsection{Thermal Analysis of Synthesized PLLA-PEG uni $_{\text {and }}$ PDLA-PEG $\mathrm{uni}_{\mathrm{u}}$}

PLLA-PEG ${ }_{\text {uni }}$ or PDLA-PEG uni $(1 \mathrm{mg})$ was weighed into aluminum pans. Unimers were analyzed using differential scanning calorimetry (DSC, TA Instruments, New Castle, DE, USA). The temperature protocol involved equilibration at $10^{\circ} \mathrm{C}$ for $2 \mathrm{~min}$ followed by a ramp-up of the temperature by $2{ }^{\circ} \mathrm{C} / \mathrm{min}$ to $160^{\circ} \mathrm{C}$, equilibration at $160^{\circ} \mathrm{C}$ for $2 \mathrm{~min}$, and ramp-down of temperature by $2{ }^{\circ} \mathrm{C} / \mathrm{min}$ to $10^{\circ} \mathrm{C}$. The lower temperature endothermic and exothermic peaks of PLLA-PEG $\mathrm{uni}_{\text {ind }}$ anLA-PEG $\mathrm{uni}_{\text {in }}$ were defined as the $\mathrm{T}_{\mathrm{m}}$ and the crystalline temperature $\left(T_{c}\right)$ of PEG, respectively. The endothermic and exothermic temperatures were defined as the $\mathrm{T}_{\mathrm{m}}$ and $\mathrm{T}_{\mathrm{c}}$ of the PLA, respectively [26].

\subsubsection{Conformation Analysis of Stereocomplex PLA-PEG Unimer (SC-PEG $\mathrm{uni}_{\mathrm{i}}$ ) in Good} Solvents Containing Different Concentrations of $\mathrm{LiBr}$

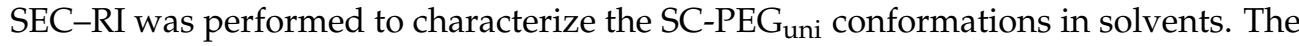
mobile phase was DMF containing $0,20,100$, or $300 \mathrm{mM} \mathrm{LiBr}$. The column oven temperature of $65^{\circ} \mathrm{C}$ simulated the preparation conditions. Other HPLC conditions have been previously reported [12]. PLLA-PEG ${ }_{\text {uni }}$ and PDLA-PEG uni $(1 \mathrm{mg}$ each) were dissolved in the corresponding LiBr concentration DMF for sample injections. The obtained chromatograms were subtracted from the blank baseline and normalized to the highest response. The relative molecular weight of the peak top $\left(\right.$ Rel. $\left.\mathrm{M}_{\mathrm{p}}\right)$ and $\mathrm{PdI}_{\text {uni }}$ were calculated from polyethylene oxide standards using the procedure described in Section 2.4.1.

\subsection{Preparation of SC-PEG NPS}

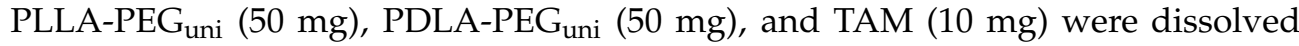
together in $1.0 \mathrm{~mL}$ of DMF containing $0,20,100$, or $300 \mathrm{mM} \mathrm{LiBr}$ (considered the good solvent). The mixture was heated at $65^{\circ} \mathrm{C}$. Nine milliliters of distilled waters and $1.0 \mathrm{~mL}$ of the organic phase were fed at a TFR of $1 \mathrm{~mL} / \mathrm{min}, 3 \mathrm{~mL} / \mathrm{min}$, and $8 \mathrm{~mL} / \mathrm{min}$ using a $\Phi 0.5 \mathrm{~mm}$ T-junction mixer (YMC, Kyoto, Japan) at $65^{\circ} \mathrm{C}$. (Figure 1) The mixture was heated and mixed at $35^{\circ} \mathrm{C}$ for the preparation temperature investigation. The resultant solutions were dialyzed to remove the solvent and residual $\mathrm{LiBr}$ with an 8-10 $\mathrm{kDa}$ MWCO dialysis membrane (Repligen, Waltham, MA, USA). Dialyzed solutions were filtered through a $0.45 \mu \mathrm{m}$ polyvinylidene fluoride filter (Merck, Kenilworth, NJ, USA). Samples were stored at $2-8{ }^{\circ} \mathrm{C}$ until further use. 


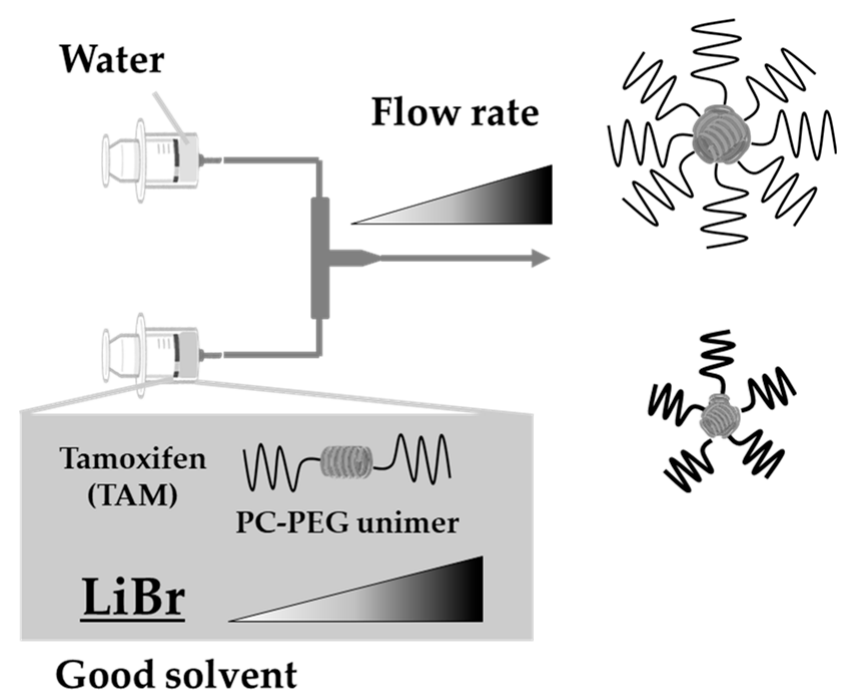

Figure 1. The schematic representation of the nanoparticle preparation.

\subsection{Characterization of TAM Loaded SC-PEG NPS}

2.6.1. Hydrodynamic Diameter $\left(\mathrm{D}_{\mathrm{h}}\right)$ and Polydispersity Index of SC-PEG NPs $\left(\mathrm{PdI}_{\mathrm{NP}}\right)$

$\mathrm{D}_{\mathrm{h}}$ and $\mathrm{PdI}_{\mathrm{NP}}$ were determined by dynamic light scattering (DLS) using a Zetasizer Nano ZS (Malvern Instruments, Malvern, UK). The measurement methods have been described previously [12]. Each sample was diluted 1:50 in $10 \mathrm{mM}$ phosphate buffer (pH 7.4) and measured by DLS.

2.6.2. Determination of Encapsulation Efficiency (EE) and Drug Loading Content by Conventional Procedure (DLC conv. $\left._{\text {. }}\right)$ and SPE (DLC SPE $_{\text {S }}$

Concentrations of TAM in NPs were determined using a previously described HPLC procedure [12]. Briefly, prepared NPs were diluted with acetonitrile (MeCN). TAM stock solution $(1 \mathrm{mg} / \mathrm{mL})$ was diluted with MeCN to prepare standard solutions of 100 to $1 \mu \mathrm{g} / \mathrm{mL}$. The samples were analyzed using HPLC. The concentration of TAM was calculated using external standards.

The concentrations of SC-PEG $\mathrm{uni}_{\text {in }}$ ine NPs were determined as previously described [12]. The prepared NPs were diluted with DMF and analyzed by SEC-RI. The

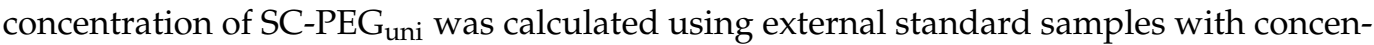
trations ranging from 2 to $8 \mathrm{mg} / \mathrm{mL}$. EE and the $\mathrm{DLC}_{\mathrm{conv}}$ were calculated as

$$
\begin{gathered}
\mathrm{EE}(\%)=\mathrm{C}_{\text {TAMload }} \times \mathrm{V}_{\text {rec }} /\left(\mathrm{C}_{\text {TAM feed }} \times \mathrm{V}_{\text {feed }}\right) \times 100 \\
\mathrm{DLC}_{\text {conv. }}(\mathrm{wt} \%)=\mathrm{C}_{\text {TAMload }} / \mathrm{C}_{\mathrm{SC}-\mathrm{PEG}} \times 100
\end{gathered}
$$

where $C_{\text {TAM load }}$ is the TAM concentration in the prepared NPs, $V_{\text {rec }}$ is the volume of the recovered NP solution, $\mathrm{C}_{\text {TAM feed }}$ is fed TAM concentration to prepare the NPs, $V_{\text {feed }}$ is the volume of solutions fed for dialysis, and $\mathrm{C}_{\mathrm{SC}-\mathrm{PEG}}$ is the weight-based concentration of SC-PEG ${ }_{\text {uni }}$ in the prepared NPs.

SPE was performed as previously described [12]. SPE columns were activated with $\mathrm{MeCN}$ and equilibrated with distilled water. The prepared NPs were then applied. The columns were washed with $20 \% \mathrm{MeCN}$ to remove adsorbed NPs. The samples were eluted with MeCN and analyzed by HPLC to determine the TAM concentrations. DLC $\mathrm{SPE}$ was calculated as

$$
\mathrm{DLC}_{\mathrm{SPE} .}(\mathrm{wt} \%)=\mathrm{C}_{\mathrm{TAMSPE}} / \mathrm{C}_{\mathrm{SC}-\mathrm{PEG}} \times 100
$$

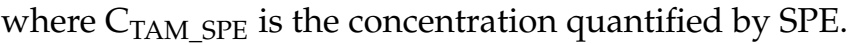


2.6.3. Determination of Association Numbers $\left(\mathrm{N}_{\mathrm{ass}}\right)$, Gyration Radius $(\mathrm{Rg})$, and Surface PEG Density

Association numbers and $R_{\mathrm{g}}$ were calculated as previously described [12]. Briefly, prepared TAM-loaded SC-PEG NPs were diluted to $5 \mathrm{mg} / \mathrm{mL}$ as SC-PEG uni $_{\text {. The prepared }}$ samples were analyzed by SEC-MALS (Wyatt Technology, Santa Barbara, CA, USA) to obtain the Berry's plot. The molecular weight $\left(\mathrm{M}_{\mathrm{NP}}\right), \mathrm{R}_{\mathrm{g}}$, and $\mathrm{N}_{\text {ass }}$ of SC-PEG were calculated using the Astra software (Wyatt, US). $\mathrm{N}_{\text {ass }}$ was calculated as

$$
\mathrm{N}_{\mathrm{ass}}=\mathrm{M}_{\mathrm{NP}} / \mathrm{Mn}_{\mathrm{uni}}
$$

The surface PEG densities were analyzed as previously described [12]. Briefly, the solvent of prepared NPs was exchanged with the Sephadex G50 column (PD-10 miniprep; Cytiva, Malborough, MA, USA) to deuterium oxide. An internal standard was added to the substituted samples. The calibration curve of mPEG $(5 \mathrm{kDa})$ was also prepared using the same procedure. The prepared samples were analyzed by ${ }^{1} \mathrm{H}-\mathrm{NMR}$ using an AVANCE III device (Bruker, Billerica, MA, USA) operating at $400 \mathrm{MHz}$. The total amount of SC-PEG was measured by SEC-RI, as described above. Surface PEG densities and surface PEG contents were calculated as

$$
\begin{gathered}
\text { Surface PEG contents }(\%)=\mathrm{C}_{\text {PEG exp. }} / \mathrm{C}_{\mathrm{SC}-\mathrm{PEG}} \times 100 \\
\Gamma=\mathrm{N}_{\mathrm{ass}} \times \text { Surface PEG contents }(\%) / 4 \pi \mathrm{R}_{\mathrm{h}}^{2} \times 100
\end{gathered}
$$

where $\Gamma$ is the density of the PEG molecules on the NP surface per $100 \mathrm{~nm}^{2}, \mathrm{C}_{\text {PEG_exp. }}$ is the concentration calculated by ${ }^{1} \mathrm{H}-\mathrm{NMR}$ in deuterium oxide, and $\mathrm{R}_{\mathrm{h}}$ is a half value of $D_{h}$ measured by DLS.

\subsubsection{Evaluation of Morphology of Lyophilized NPs}

The morphologies of lyophilized NPs were evaluated with field emission scanning electron microscopy (FE-SEM) according to a previously published method with slight modifications [27]. Lyophilized NPs were sputter-coated with a layer of osmium with the Neoc osmium coater (Meiwafosis, Japan). Prepared samples were observed with FE-SEM (JEOL JSM-IT500HR LV, Japan) and operated at $10 \mathrm{kV}$.

2.7. Preparation of "PEG Sparse- $D_{h}$ Small" NP (NP Sparse-Small $)$ and "PEG Dense- $D_{h}$ Large" NP (NP Dense-Large $)$ for PK Studies

${ }^{111}$ In-labeled SC-PEG NPs were prepared as previously described [12]. PLLA-PEGDTPA was dissolved in DMF followed by the addition of distilled water. ${ }^{111} \mathrm{InCl}_{3}$ and $10 \mathrm{mM}$ citrate buffer ( $\mathrm{pH}$ 5.5) were added. The reacted solutions were purified using PD-10 columns, and the water was evaporated. The resulting PLLA-PEG-DTPA- ${ }^{111}$ In ( ${ }^{111}$ In-PLLA-PEG) was dissolved in DMF containing $20 \mathrm{mM}$ or $100 \mathrm{mM}$ LiBr. Radioactivity was measured using a 1480 Wizard $^{\mathrm{TM}} 3$ gamma counter (PerkinElmer, Waltham, MA, USA).

PLLA-PEG uni $_{\text {and PDLA-PEG }}$ (50 mg each) were dissolved in $0.15 \mathrm{~mL}$ of DMF containing $20 \mathrm{mM}$ or $100 \mathrm{mM} \mathrm{LiBr}$ to prepare the $\mathrm{NP}_{\text {Sparse-Small }} \mathrm{NPs}$ or $\mathrm{NP}_{\text {Dense-Large, }}$ respectively. Ten microliters of ${ }^{111} \mathrm{In}$-PLLA-PEG with a radioactivity equivalent to $200 \mathrm{kBq}$ was added. TAM $(10 \mathrm{mg})$ was dissolved in $0.15 \mathrm{~mL}$ of DMF, and $10 \mu \mathrm{L}$ of ${ }^{14} \mathrm{C}$-TAM having an equivalent radioactivity to $200 \mathrm{kBq}$ was added. NPs were prepared as described in Section 2.5. TFRs of 3 and $8 \mathrm{~mL} / \mathrm{min}$ were used to prepare the $\mathrm{NP}_{\text {Sparse-Small }}$ and $\mathrm{NP}_{\text {Dense-Large, }}$ respectively. After dialysis with $9 \%$ sucrose, the samples were stored at 2-8 ${ }^{\circ} \mathrm{C}$ until administration.

\subsection{Evaluations of PK Profiles of Radiolabeled PLA-PEG NPs Loaded with TAM}

The ${ }^{111}$ In-labeled PLA-PEG NPs ( ${ }^{111}$ In-SC-PEG NPs) loaded with ${ }^{14} \mathrm{C}$-labeled TAM $\left({ }^{14} \mathrm{C}\right.$-TAM) were administered by intravenous injection via the tail vein to 6-week-old ddY mice (370 kBq ${ }^{111} \mathrm{In}$-SC-PEG NPs $/ \mathrm{kg}, 320 \mathrm{kBq}{ }^{14} \mathrm{C}$-TAM $\left./ \mathrm{kg}\right)$. At $0.083,0.5,1,3,6$, and 
$24 \mathrm{~h}$ after injection, blood was collected from the vena cava under isoflurane anesthesia, and the mice were sacrificed. The liver and spleen were removed, rinsed with saline, and blotted dry, and the total organ weight was weighed. The collected blood was centrifuged for $5 \mathrm{~min}$ at $2000 \times g$ to obtain plasma.

To measure ${ }^{111}$ In radioactivity, the collected organs and $100 \mu \mathrm{L}$ of plasma were transferred to counting tubes, and the radioactivity of the samples was measured using the aforementioned 1480 Wizard $^{\mathrm{TM}} 3$ gamma counter $[12,28]$.

${ }^{14} \mathrm{C}$-TAM radioactivity was measured as previously described [12,29] using a model LSC-6100 liquid scintillation counter (Aloka, Mitaka, Japan).

The ${ }^{111}$ In and ${ }^{14} \mathrm{C}$ radioactivities were normalized based on the percentage of the dose/mL for plasma and on the percentage of dose/organ ( $\mathrm{g}$ ) for other tissues. The area under the curve (AUC) of ${ }^{111}$ In-SC-PEG NPs and ${ }^{14}$ C-TAM was calculated using the trapezoidal method. To estimate the total clearance $\left(\mathrm{CL}_{\text {tot }}\right)$, half-life $\left(\mathrm{T}_{1 / 2 \alpha}\right.$ and $\left.\mathrm{T}_{1 / 2 \beta}\right)$, distribution volume $\left(\mathrm{V}_{\mathrm{d}}\right)$, and initial plasma concentrations $\left(\mathrm{C}_{0}\right)$ of both isotopes, normalized radioactivities in the plasma were analyzed using the MULTI nonlinear least-squares program [30]. Two-compartment model analysis was performed.

\subsection{Statistical Analyses}

Statistical significance was analyzed by the Student's $t$-test for multiple groups at a significance level of $p<0.05$. To analyze the response surface of $\mathrm{D}_{\mathrm{h}}$ and $\mathrm{PdI} \mathrm{IP}_{\mathrm{NP}}$, two-way ANOVA analysis was performed using Design-Expert software (Stat-Ease, Minneapolis, MN, USA) with a significance level of $p<0.05$.

\section{Results}

\subsection{Synthesis and Characterizations of Different PDLA-PEG $G_{u n i}$ and PLLA-PEG}

Table 1 presents $\mathrm{Mn}_{\text {uni }}$ and $\mathrm{PdI}_{\text {uni }}$ data of PDLA-PEG $\mathrm{uni}_{\text {and PLLA-PEG }}$ uni. The $\mathrm{Mn}_{\text {uni }}$ of the PLA domains was approximately 12,000, in good agreement with the theoretical values. $\mathrm{PdI}_{\text {uni }}$ was evaluated using SEC-RI analysis. The synthesized polymers were monomodal (Figure S1A, Supplementary Materials).

Table 1. Number-based molecular weight and polydispersity index of synthesized PLA-PEG unimer.

\begin{tabular}{|c|c|c|c|}
\hline Unimers & Mn PEG (g/mole) & Mn * PLA (g/mole) & $\mathrm{PdI}_{\text {uni }}$ ** \\
\hline PDLA-PEG ${ }_{\text {uni }}$ & 5000 & 12,007 & 1.78 \\
\hline PLLA-PEG ${ }_{\text {uni }}$ & 5000 & 12,497 & 1.82 \\
\hline
\end{tabular}

Figure 2A,B show the DSC plots of PDLA-PEG uni $_{\text {and PLLA-PEG }}$ uni. With the temperature ramp-up from $10^{\circ} \mathrm{C}$ to $160{ }^{\circ} \mathrm{C}$, endothermic peaks of PEG melting were observed at approximately $50{ }^{\circ} \mathrm{C}$ in both copolymers, following endothermic peaks of PLA melting, which were observed at $139{ }^{\circ} \mathrm{C}$ and $153{ }^{\circ} \mathrm{C}$, respectively (Figure 2A and Table 2). With the temperature ramp-down from $160^{\circ} \mathrm{C}$ to $10^{\circ} \mathrm{C}$, exothermic peaks of PLA crystallization were observed at $97^{\circ} \mathrm{C}$ and $119^{\circ} \mathrm{C}$ in PDLA-PEG uni $_{\text {and PLLA-PEG }}$, respectively. Exothermic peaks of PEG crystallization were observed at approximately $25^{\circ} \mathrm{C}$ (Figure $2 \mathrm{~B}$ and Table 2).

Table 2. Melting temperature (Tm) and crystalline temperature $(\mathrm{Tc})$ of synthesized PLA-PEG characterized by differential scanning calorimetry.

\begin{tabular}{ccccc}
\hline Unimers & PEG $_{\mathbf{m}}\left({ }^{\circ} \mathbf{C}\right)$ & PEG $_{\mathbf{c}}\left({ }^{\circ} \mathbf{C}\right)$ & PLA $_{\mathbf{m}}\left({ }^{\circ} \mathbf{C}\right)$ & PLA T $_{\mathbf{c}}\left({ }^{\circ} \mathbf{C}\right)$ \\
\hline PDLA-PEG $_{\text {uni }}$ & $48.0 \pm 2.0$ & $25.2 \pm 0.6$ & $139 \pm 0.2$ & $96.7 \pm 0.1$ \\
\hline PLLA-PEG $_{\text {uni }}$ & $46.4 \pm 0.8$ & $21.7 \pm 0.1$ & $153 \pm 0.5$ & $119 \pm 0.1$ \\
\hline
\end{tabular}


(A)

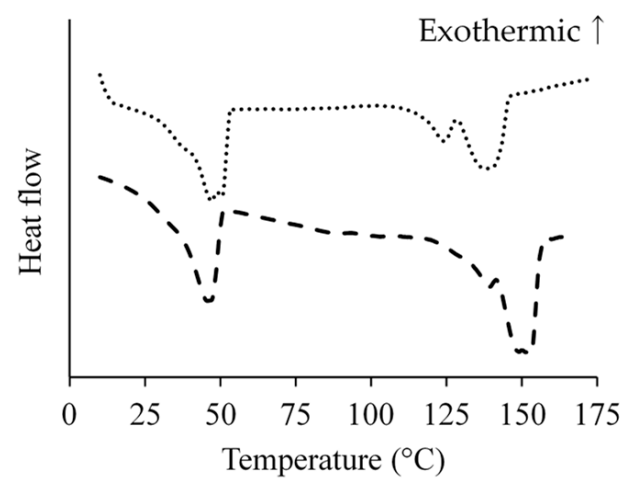

(B)

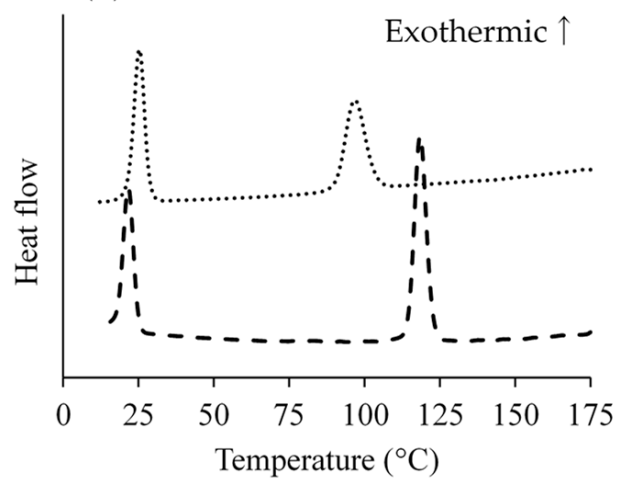

Figure 2. DSC plot of PDLA-PEGuni and PLLA-PEGuni. In panels $A$ and $B$, the total heat flow was plotted as a function of temperature when the temperature was raised from $10^{\circ} \mathrm{C}$ to $160^{\circ} \mathrm{C}(\mathrm{A})$ and lowered from $160^{\circ} \mathrm{C}$ to $10^{\circ} \mathrm{C}$ (B). The dotted line and dashed line indicate heat flow of PDLA-PEGuni and PLLA-PEGuni, respectively.

\subsection{Physicochemical Properties of NPs by Preparing at Different Temperature}

SC-PEG NPs were prepared at $35^{\circ} \mathrm{C}$ and $65^{\circ} \mathrm{C}$ and evaluated by DLS, SEC-MALS, and ${ }^{1} \mathrm{H}-\mathrm{NMR}$. The $\mathrm{R}_{\mathrm{h}}$ of SC-PEG NPs prepared at $65^{\circ} \mathrm{C}\left(\mathrm{NP}_{\text {prep. }} 65^{\circ} \mathrm{C}\right)$ and $35^{\circ} \mathrm{C}\left(\mathrm{NP}_{\text {prep. } 35^{\circ} \mathrm{C}}\right)$ were comparable, though the $\mathrm{PdI}_{\text {nano }}$ of $\mathrm{NP}_{\text {prep. } 65^{\circ} \mathrm{C}}$ were significantly lower than those


polydisperse than $\mathrm{NP}_{\text {prep. } 65^{\circ} \mathrm{C}}$ (Figure $3 \mathrm{~B}$ ). The $\mathrm{R}_{\mathrm{g}}$ value of $\mathrm{NP}_{\text {prep. } 35^{\circ} \mathrm{C}}$ at an early retention time was larger than the $\mathrm{R}_{\mathrm{g}}$ value of $\mathrm{NP}_{\text {prep. } 65^{\circ} \mathrm{C} .}{ }^{1} \mathrm{H}-\mathrm{NMR}$ analysis revealed that surface PEG densities of $\mathrm{NP}_{\text {prep. } 65^{\circ} \mathrm{C}}$ were significantly higher than those of $\mathrm{NP}_{\text {prep }} 35^{\circ} \mathrm{C}$ (Figure 3C). Therefore, $65^{\circ} \mathrm{C}$ was selected as the processing temperature for further SC-PEG NP preparation.

\subsection{Copolymer Conformation in Different LiBr Concentrations}

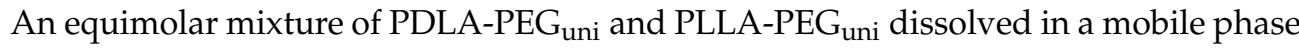
containing $\mathrm{LiBr}$ was measured by SEC-RI (Figure 4). Aggregates of unimers (retention time $6.6 \mathrm{~min}$ ) were evident in the mobile phase that did not contain LiBr. In contrast, a mobile phase containing $20 \mathrm{mM} \mathrm{LiBr}$ displayed a monomodal molecular weight distribution of

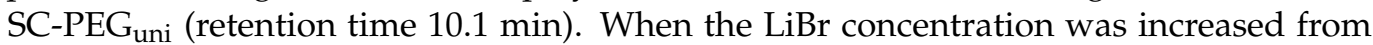
20 to $300 \mathrm{mM}$, the peak top of the copolymers shifted earlier, and all were monomodal. The relative molecular weight was calculated based on the polyethylene oxide standard

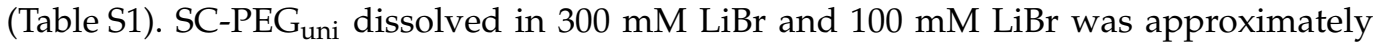
2.5 times and 2 times larger, respectively, than those dissolved in $20 \mathrm{mM} \mathrm{LiBr}$. The PdI of SC-PEG ${ }_{\text {uni }}$ in $300 \mathrm{mM} \mathrm{LiBr}$ was 3.52, suggesting that the unimers were polydisperse.

\subsection{Physicochemical Properties of NPs Prepared by Different LiBr Concentrations and TFR}

\subsubsection{DLC Calculated by Conventional Method and SPE and Release Profile of TAM}

Figure 5 presents data of $\mathrm{DLC}_{\text {conv. }}(\mathrm{A})$ and $\mathrm{DLC}_{\mathrm{SPE}}(\mathrm{B})$. In the case of NPs prepared with a solvent containing $300 \mathrm{mM} \mathrm{LiBr}$, the DLC calculated by both procedures was significantly lower than those of the other processing conditions. EE displayed a similar trend (Figure S2A). DLC $\mathrm{SPE}$ was approximately half that of $\mathrm{DLC}_{\text {conv. }}$. This means that approximately half of the TAM was adsorbed onto the surface of the NPs [12]. The TFR did not significantly affect the drug loading, but both DLC values were slightly increased by slowing the TFR.

Figure S2B shows the release profiles of TAM from SC-PEG NPs, except for NPs prepared with $300 \mathrm{mM} \mathrm{LiBr}$. All NPs released TAMs until $24 \mathrm{~h}$ after release was stopped until $48 \mathrm{~h}$. TAM was released from the NPs again until $96 \mathrm{~h}$. 
(A)

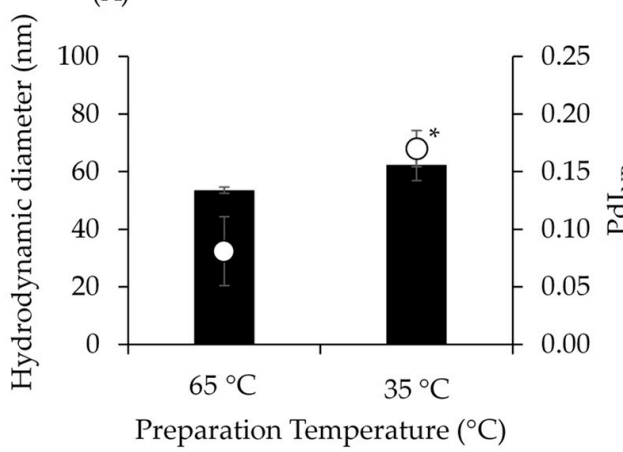

(C)

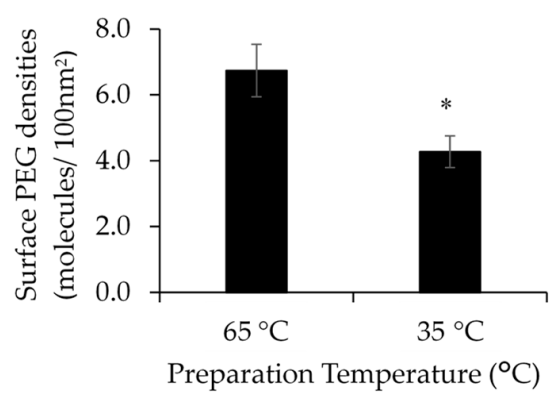

(B)

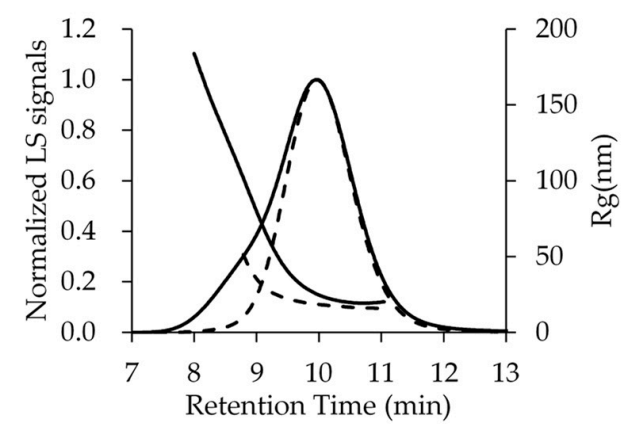

Figure 3. Characteristics of SC-PEG NPs prepared in different temperatures. Panel (A) shows the hydrodynamic diameters $\left(\mathrm{D}_{\mathrm{h}}\right)$ and polydispersity index $\left(\mathrm{PdI}_{\mathrm{NP}}\right)$. Solid bars and open circles indicate $\mathrm{Dh}$ (left axis) and $\mathrm{PdI}_{\mathrm{NP}}$ (right axis), respectively. Results are expressed as the mean \pm standard deviation of three samples. The experiments were independently performed three times; ${ }^{*} p<0.05$. Panel (B) represents the SEC-MALS chromatogram. Solid lines and dashed lines indicate NPs prepared at $35^{\circ} \mathrm{C}$ and $65^{\circ} \mathrm{C}$, respectively. Left and right axis represents light scattering signals and gyration radius $\left(\mathrm{R}_{\mathrm{g}}\right)$, respectively. Panel $(\mathrm{C})$ shows surface PEG densities. Results are expressed as the mean \pm standard deviation of three samples. The experiments were independently performed three times; ${ }^{*} p<0.05$.

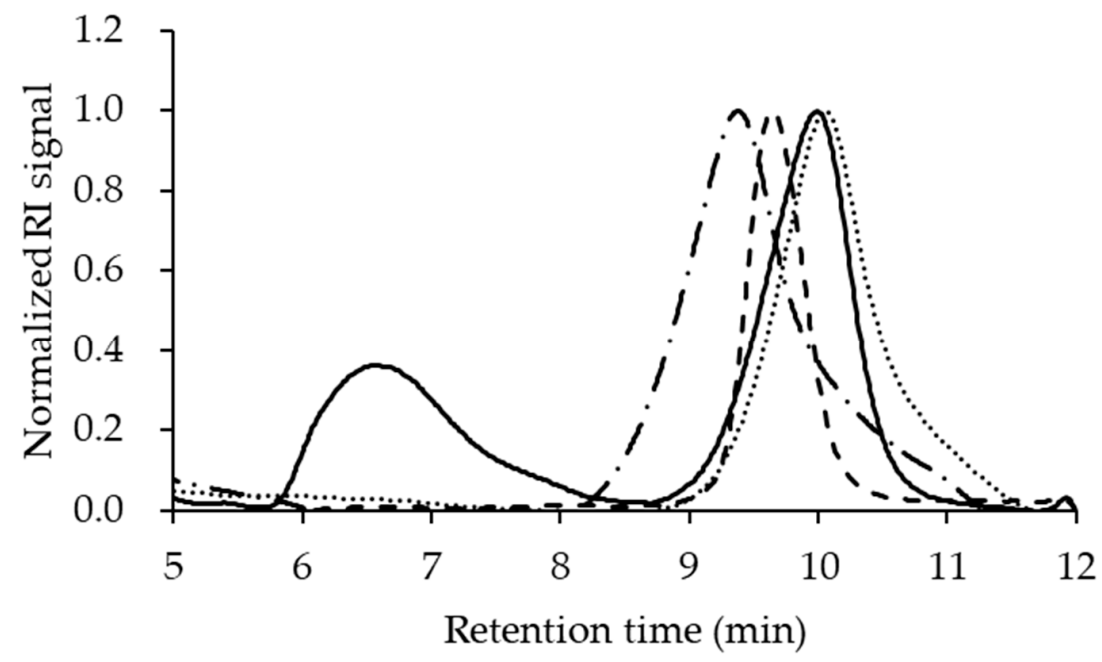

Figure 4. Size-exclusion chromatograms of SC-PEG $\mathrm{uni}_{\text {in }}$ in solvents containing different concentrations of $\mathrm{LiBr}$. Normalized refractive index signals were plotted as a function of retention time. The solid line, dotted line, dashed line, and chain line indicate DMF containing $0 \mathrm{mM}, 20 \mathrm{mM}, 100 \mathrm{mM}$, and $300 \mathrm{mM}$ LiBr, respectively. 
(A)

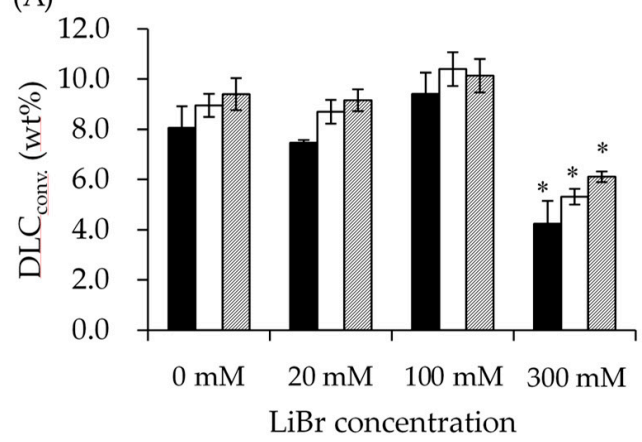

(B)

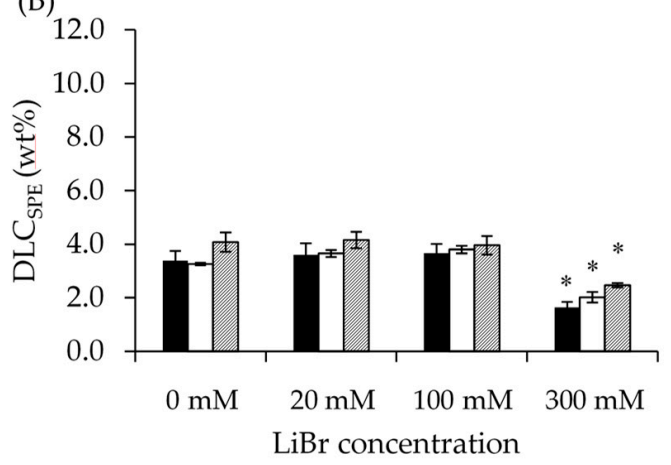

Figure 5. Drug loading contents (DLC) quantified by conventional method (DLC $\mathrm{Conv}_{\text {, }}$ A) and solid-phase extraction (DLC $\mathrm{SPE}_{\mathrm{S}}, \mathrm{SPE}$ ) method (B). Filled bars, open bars, and hatched bars indicate flow rates of $8 \mathrm{~mL} / \mathrm{min}, 3 \mathrm{~mL} / \mathrm{min}$, and $1 \mathrm{~mL} / \mathrm{min}$, respectively. Results are expressed as the mean \pm standard deviation of three samples. The experiments were independently performed three times; ${ }^{*} p<0.05$ to all other $\mathrm{LiBr}$ concentrations.

3.4.2. $\mathrm{D}_{\mathrm{h}}, \mathrm{PdI}_{\mathrm{NP}}$, and Surface PEG Densities of SC-PEG NPs Prepared by Different Processing Parameters

$\mathrm{D}_{\mathrm{h}}$ and $\mathrm{PdI}_{\mathrm{NP}}$ of SC-PEG NPs are shown in Figure S3A,B, respectively. The $\mathrm{D}_{\mathrm{h}}$ of NPs ranged from 54 to $122 \mathrm{~nm}$ by changing the TFR and the concentration of $\mathrm{LiBr}$ in solvent. All $\mathrm{PdI}_{\mathrm{NP}}$ were $<0.2$, indicating monodispersion.

The effects of the interactions of $\mathrm{LiBr}$ concentrations and TFR on $\mathrm{D}_{\mathrm{h}}$ and $\mathrm{PdI}_{\mathrm{NP}}$ were evaluated using the response surface method. The results are presented in Figure 6A,B, respectively. Both were fitted using a quadratic model. The F-values of the models were $115\left(p=3.0 \times 10^{-17}\right)$ for $\mathrm{D}_{\mathrm{h}}$ and $12.0\left(p=1.9 \times 10^{-5}\right)$ for $\mathrm{PdI}_{\mathrm{NP}}$, indicating that both models were significant. The lack of fit for the F-value was not significant. The $\mathrm{R}^{2}$ values of the response surface were 0.91 for $D_{h}$ and 0.53 for $P d I_{N P}$. Both $D_{h}$ and $P_{d I_{N P}}$ increased with increasing $\mathrm{LiBr}$ concentration and decreasing TFR.

The $D_{h}$ and surface PEG densities correlated well $\left(R^{2}=0.64\right.$, Figure $\left.6 C\right)$. The surface PEG densities of SC-PEG NPs exhibited the same trend as that of $D_{h}$ (Figure S3C). Surface PEG densities ranged from 6.70 to 16.6 molecules $/ 100 \mathrm{~nm}^{2}$. These results indicated that a faster TFR resulted in $\mathrm{D}_{\mathrm{h}}$ and surface PEG densities of NPs that were smaller and sparser. The morphology of prepared NPs was spherical (Figure 5). The lower panel shows the morphology of NPs prepared with $100 \mathrm{mM} \mathrm{LiBr} / \mathrm{TFR} 3 \mathrm{~mL} / \mathrm{min}$, which was slightly larger than that of NPs prepared with $20 \mathrm{mM} \mathrm{LiBr} / \mathrm{TFR} 8 \mathrm{~mL} / \mathrm{min}$, (the upper panel).

\subsection{Plasma PK Profile and Tissue Distributions of SC-PEG NPs with Different Surface PEG Densities and $D_{h}$ Prepared Using Different Processing Parameters}

As the surface PEG densities and $D_{h}$ of SC-PEG NPs had a trade-off relationship, two types of SC-PEG NPs with different surface PEG densities and $R_{h}$ were prepared to investigate mouse $\mathrm{PK}$ and tissue distribution. One was $\mathrm{NP}_{\text {Sparse-Small }}$ with surface densities and $R_{h}$ of 7.90 molecules $/ 100 \mathrm{~nm}^{2}$ and $61 \mathrm{~nm}$, respectively, prepared with a solvent containing $20 \mathrm{mM} \mathrm{LiBr}$ and $8 \mathrm{~mL} / \mathrm{min}$ of TFR. The other was $\mathrm{NP}_{\text {Dense-Large }}$ with surface densities and $R_{h}$ of 16.6 molecules $/ 100 \mathrm{~nm}^{2}$ and $105 \mathrm{~nm}$, respectively, prepared with a solvent containing $100 \mathrm{mM} \mathrm{LiBr}$ and $3 \mathrm{~mL} / \mathrm{min}$ of TFR.

These two types of NPs were injected into mice, and PK and tissue distributions were evaluated (Figure 7 and Table 3). $\mathrm{NP}_{\text {Dense-Large }}$ had higher plasma concentrations and AUCs of ${ }^{111}$ In-SC-PEG NPs and ${ }^{14} \mathrm{C}-\mathrm{TAM}$ compared to NP $\mathrm{NParse}_{\text {Small }}$ (Figure 7A,D and Table 3). $\mathrm{NP}_{\text {Dense-Large }}$ also displayed lower $\mathrm{V}_{\mathrm{d}}$ and $\mathrm{CL}_{\text {tot }}$, and a longer $\mathrm{T}_{1 / 2 \beta}$ of ${ }^{111} \mathrm{In}$-SCPEG NPs and ${ }^{14} \mathrm{C}$-TAM than $\mathrm{NP}_{\text {Sparse-Small }}$ calculated by two-compartment models. $\mathrm{T}_{1 / 2 \alpha}$ were comparable to both NPs in terms of ${ }^{111}$ In-SC-PEG NPs and ${ }^{14}$ C-TAM. Both $C_{0}$ values

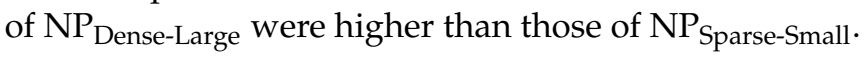




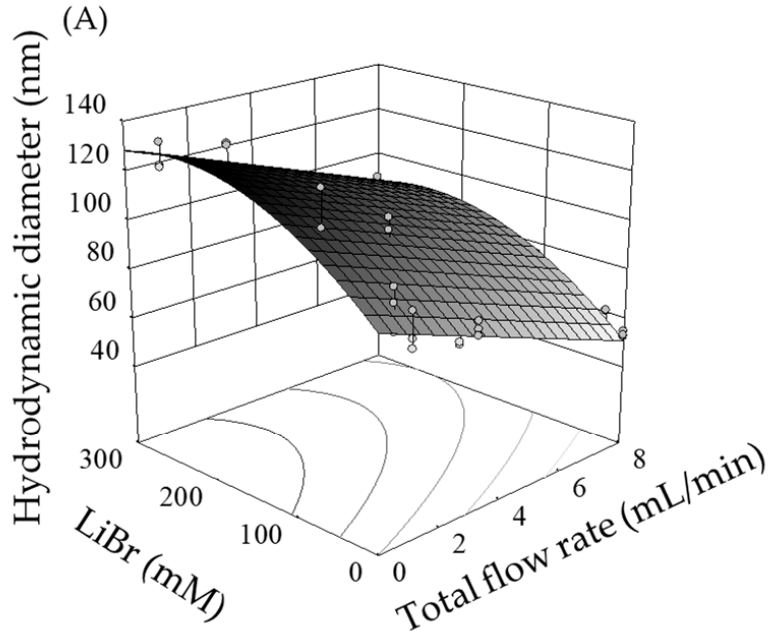

(C)

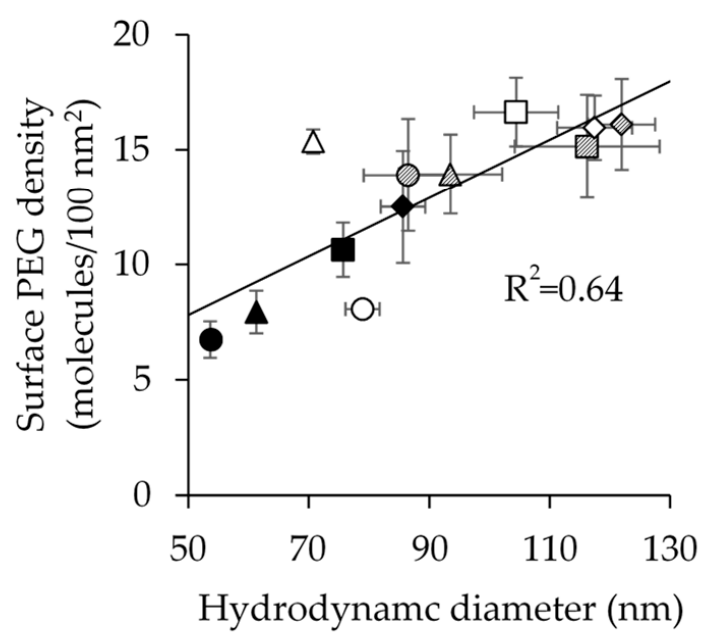

(B)

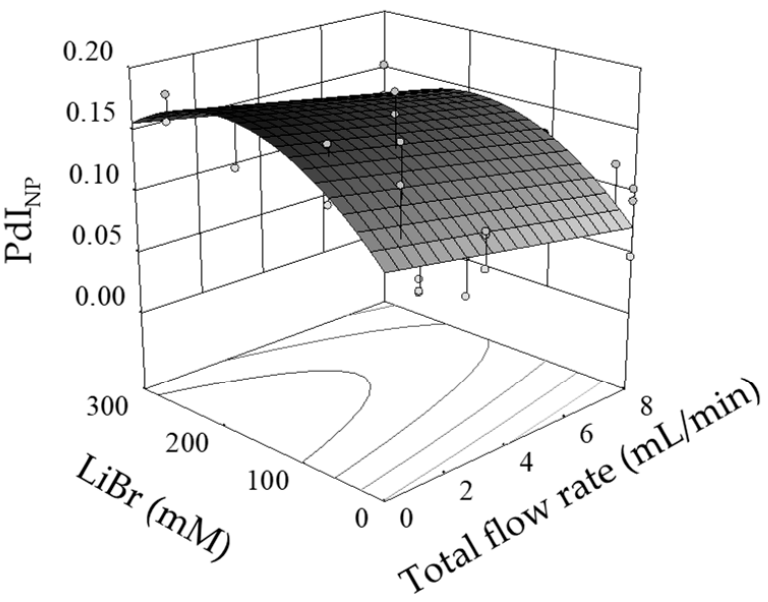

(D)
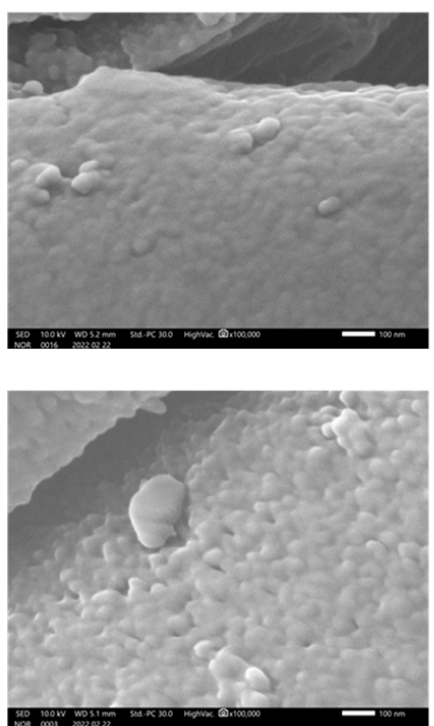

Figure 6. Response surface of hydrodynamic diameters $\left(\mathrm{D}_{\mathrm{h}}\right)$ and polydispersity $\left(\mathrm{PdI}_{\mathrm{NP}}\right)$ of nanoparticles (NPs), relationship between $D_{h}$ and surface PEG densities, and FE-SEM image of lyophilized NPs. Panels $(\mathbf{A}, \mathbf{B})$ show the response surface of $\mathrm{D}_{\mathrm{h}}$ and $\mathrm{PdI}_{\mathrm{NP}}$, respectively. Circle symbols indicate individual values. Response surfaces were fitted by quadratic models. Panel (C) indicates surface PEG densities plotted as a function of $D_{h}$. Closed, open, and hatched symbols indicate TFRs of $8 \mathrm{~mL} / \mathrm{min}, 3 \mathrm{~mL} / \mathrm{min}$, and $1 \mathrm{~mL} / \mathrm{min}$, respectively. Circles, triangles, squares, and diamonds indicate LiBr concentrations $=0 \mathrm{mM}, 20 \mathrm{mM}, 100 \mathrm{mM}$, and $300 \mathrm{mM}$, respectively. Results are expressed as the mean \pm standard deviation of three samples. Correlation curves were fitted by a linear model using the least squares method. Panel (D) shows the FE-SEM image magnified 100,000 times. The upper panels show morphologies of lyophilized NPs prepared with $20 \mathrm{mM} \mathrm{LiBr} / \mathrm{TFR} 8 \mathrm{~mL} / \mathrm{min}$. The lower panel shows the morphology of lyophilized NPs prepared with $100 \mathrm{mM} \mathrm{LiBr} / \mathrm{TFR} 3 \mathrm{~mL} / \mathrm{min}$. Bars represent $100 \mathrm{~nm}$ scales.

Tissue distributions of ${ }^{111}$ In-SC-PEG NPs (Figure 7B,C) and ${ }^{14} \mathrm{C}-\mathrm{TAM}$ (Figure 7E,F) in the liver and spleen are shown. In the liver, $\mathrm{NP}_{\text {Dense-Large }}$ displayed significantly reduced tissue concentrations of ${ }^{111}$ In-SC-PEG NPs and ${ }^{14}$ C-TAM compared to NP Sparse-Small. Tissue concentrations in the spleen also showed the same trends in the liver, but they were not significant in both ${ }^{111}$ In-SC-PEG NPs and ${ }^{14}$ C-TAM. 
(A)

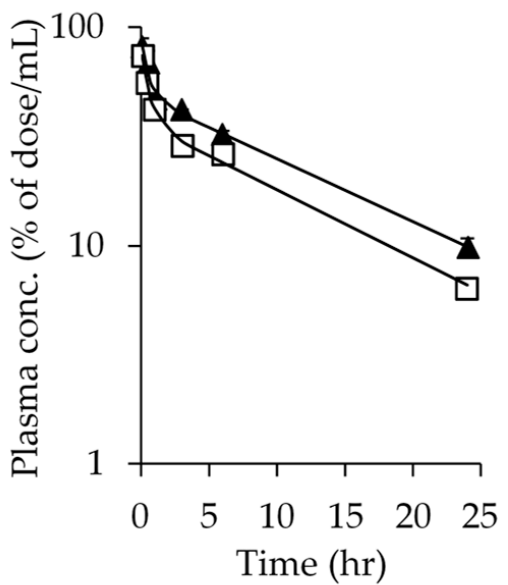

(D)



(B)

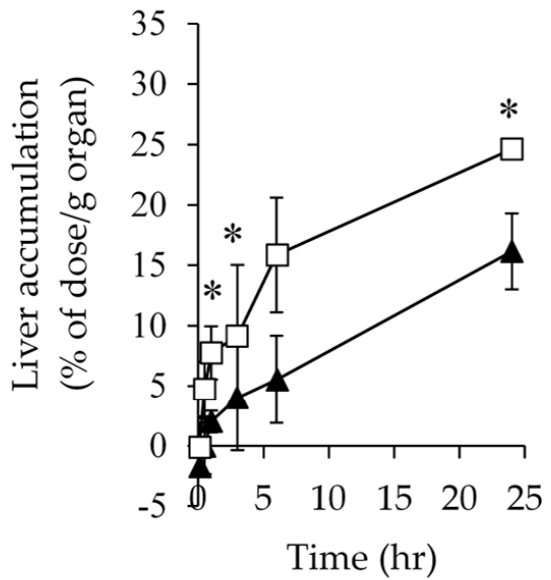

(E)

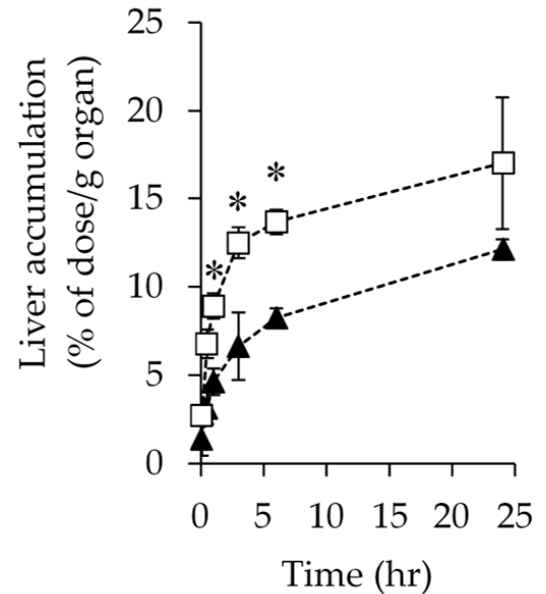

(C)



(F)

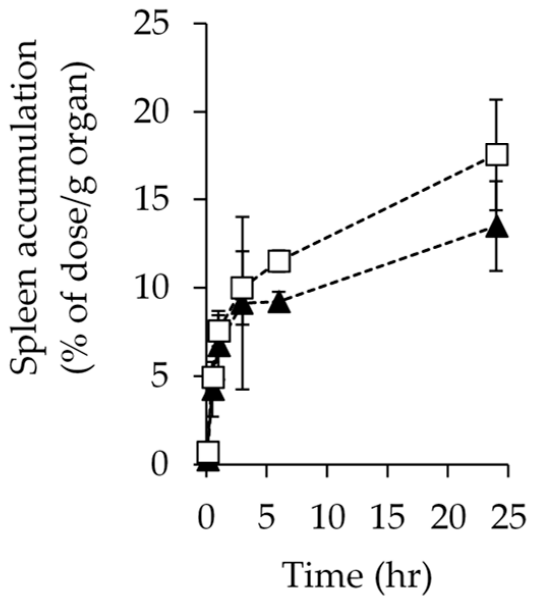

Figure 7. Pharmacokinetics and tissue distributions of ${ }^{14} \mathrm{C}$-TAM-loaded ${ }^{111}$ In-SC-PEG nanoparticles (NPs). Panels (A-C) show normalized plasma concentration, liver distributions, and spleen distributions of ${ }^{111}$ In-SC-PEG NPs, respectively. Panels (D-F) show normalized plasma concentration, liver distributions, and spleen distributions of ${ }^{14} \mathrm{C}$-TAM, respectively. Filled triangles and open squares indicate SC-PEG NPs prepared by LiBr $100 \mathrm{mM}$ at a flow rate of $3 \mathrm{~mL} / \mathrm{min}$, and LiBr $20 \mathrm{mM}$ at a flow rate of $8 \mathrm{~mL} / \mathrm{min}$, respectively. Solid lines and dashed lines in panels $A$ and $D$, respectively, indicate two-compartment model fitted curves. Results are expressed as mean $\pm \mathrm{SD}$ of three mice: ${ }^{*} p<0.05$.

Table 3. Pharmacokinetics parameters of PEG Small-Sparse NPs and PEG Large-Dense NPs.

\begin{tabular}{|c|c|c|c|c|c|c|}
\hline & $\begin{array}{c}\text { Plasma AUC * } \\
(\mathrm{h} * \% \text { of dose } / \mathrm{mL})\end{array}$ & $\begin{array}{c}\mathrm{T}_{1 / 2 \alpha^{* *}} \\
(\mathrm{~min})\end{array}$ & $\begin{array}{c}\mathrm{T}_{1 / 2 \beta}{ }^{* *} \\
(\mathrm{~min})\end{array}$ & $\begin{array}{l}\mathrm{CL}_{\text {tot }} * * \\
(\mathrm{~mL} / \mathrm{min})\end{array}$ & $\begin{array}{l}\mathrm{V}_{\mathrm{d}} \text { ** } \\
(\mathrm{mL})\end{array}$ & $\begin{array}{c}\mathrm{C}_{0}^{* *} \\
(\% \text { of dose } / \mathrm{mL})\end{array}$ \\
\hline \multicolumn{7}{|c|}{${ }^{111}$ In-SC-PEG } \\
\hline $\mathrm{NP}_{\text {Large-Dense }}$ & 640 & 0.374 & 10.5 & 0.133 & 1.95 & 88.9 \\
\hline $\mathrm{NP}_{\text {Small-Sparse }}$ & 497 & 0.416 & 9.67 & 0.184 & 2.45 & 80.1 \\
\hline \multicolumn{7}{|c|}{${ }^{14} \mathrm{C}-\mathrm{TAM}$} \\
\hline $\mathrm{NP}_{\text {Large-Dense }}$ & 441 & 0.570 & 11.7 & 0.179 & 2.89 & 61.8 \\
\hline $\mathrm{NP}_{\text {Small-Sparse }}$ & 362 & 0.343 & 8.35 & 0.262 & 3.06 & 55.6 \\
\hline
\end{tabular}

* Calculated using the trapezoidal method. The mean values of the three mice with normalized plasma concentrations were used. **: Calculated by the two-compartment model. The mean values of the three mice with normalized plasma concentrations were used. 


\section{Discussion}

\subsection{Preparation Temperature Affects PdI $I_{N P}$ and Surface PEG Densities of SC-PEG NPs}

The preparation temperature was affected by the $\mathrm{PdI}_{\mathrm{NP}}$ and surface PEG densities of the NPs (Figure 3). This was because the conformations of the PEG chains could be changed by temperature, as indicated by the DSC measurements (Figure 2). The PEG chain $\mathrm{T}_{\mathrm{m}}$ of the synthesized PDLA-PEG $\mathrm{uni}_{\text {and PLLA-PEG }}$ uni were $48.0^{\circ} \mathrm{C}$ and $46.4^{\circ} \mathrm{C}$, respectively (Figure $2 \mathrm{~A}$ ). Below the $\mathrm{T}_{\mathrm{m}}$, PEG chains would not interact with the solvent, leading to unimer aggregation. When unimers were dissolved in DMF, the solution was clear and aggregates were not observed, even at $35^{\circ} \mathrm{C}$. When NPs were prepared at $35^{\circ} \mathrm{C}$, the PEG chains could be partially embedded in the PLA core. This could be the reason why $\mathrm{NP}_{\text {prep } 35^{\circ} \mathrm{C}}$ showed polydisperse and sparse surface PEG densities.

Previous studies have reported that bulk PEG chain conformations in di-block copolymers change depending on their crystalline temperature [31,32]. Moreover, it was also reported that PLA-PEG or PLGA-PEG NPs prepared by anti-solvent precipitation feature embedded PEG chains in the core [33,34].

\subsection{Characteristics of SC-PEG NPs Were Controlled by LiBr Concentrations and TFR}

Unimer conformations were changed by the addition of $\mathrm{LiBr}$ (Figure 4). Previous reports revealed that $\mathrm{LiBr}$ altered the conformations of macromolecules $[23,24]$. Our results from the evaluation of conformation are in good agreement with these reports. It was speculated that the addition of $\mathrm{LiBr}$ up to $20 \mathrm{mM}$ resulted in dissociating the interactions between the hydrophilic domain of the unimer because previous research elucidated that $\mathrm{LiBr}$ shields the dipole moment between polymers [35]. In contrast, the addition of over $100 \mathrm{mM} \mathrm{LiBr}$ would lead to the salting-out effect, which resulted in associating the unimers with their hydrophobic domains. These would contribute the increase in $\mathrm{N}_{\text {ass }}$ in the formation of NPs. Previous research showed that the increment in $\mathrm{LiBr}$ in the DMF increased polymer-polymer interactions [36]. It was also reported that the size of lignin nanoparticles prepared by anti-solvent precipitations was controlled by structures of lignin in the solvent. The solution structures of lignin were changed by ion strength or $\mathrm{pH}$ [37]. Our observations are consistent with these reports. In addition, other reports also revealed that a fast flow rate or high Reynolds number reduces the particle size in anti-solvent precipitation preparations [38-40]. As the diffusion of a good solvent in the aqueous phase was faster at a fast flow rate, a smaller number of unimers were associated with decreased hydrophobic effects. Our results are in good agreement with this observation. Our preparation procedures combined the two aforementioned effects to regulate $D_{h}$ and $\mathrm{PdI}_{\mathrm{NP}}$. Higher concentrations of $\mathrm{LiBr}$ and slower TFR allowed more SC-PEG uni to associate. The slower diffusion of solvent and more associated unimers in the solvent resulted in a larger $\mathrm{D}_{\mathrm{h}}$ and wider PdI $\mathrm{NP}$ of SC-PEG NP. However, the PdI $\mathrm{I}_{\mathrm{NP}}$ of all prepared NPs was $<0.2$, indicating that the prepared NPs were monodispersed. Due to these two processing parameters, the $D_{h}$ of SC-PEG NP could be more widely controlled, from 53 to $122 \mathrm{~nm}$, compared to using a single process parameter alone (Figure 6A,B).

Surface PEG densities were also correlated with the $\mathrm{D}_{\mathrm{h}}$ of SC-PEG NPs (Figure 6C). This phenomenon was reasonable because the specific surface areas of the SC-PEG NPs increased when their $D_{h}$ decreased. The surface PEG contents indicated that the ratio of surface-exposed PEG chains to whole PEG chains was not changed by changing the processing parameters (Figure S3D). Previous studies also reported that surface PEG densities were controlled by adding hydrophobic polymers to NP systems to decrease the specific surface areas or conjugating the PEG chain to NPs to increase the surface densities $[7,41]$. Our present results are consistent with the previous data in terms of specific surface area governed by surface PEG densities.

Figure 8 shows a brief summary of the relationship between process parameters in the preparation of NPs. The addition of LiBr in the good solvent caused the association of the polymer, and the slower flow rate decreased the diffusion rate of the good solvent, which led to increasing $\mathrm{N}_{\text {ass }}$. $\mathrm{D}_{\mathrm{h}}$ was increased by increasing $\mathrm{N}_{\mathrm{ass}}$, and the specific surface areas 
of NPs were decreased, which resulted in the increase in surface PEG densities. These were the reasons the processing parameters affected the nanoparticle characteristics.

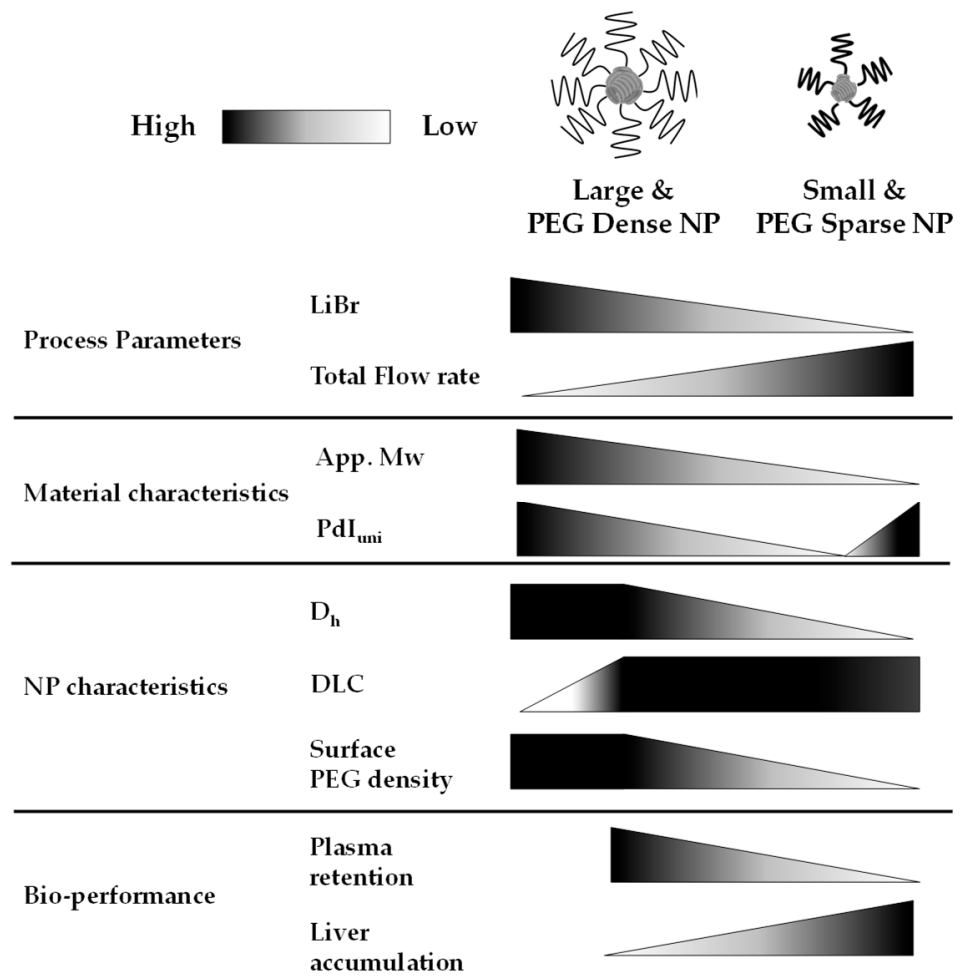

Figure 8. Schematic summary of the relationship between process parameters in the preparation of NPs.

Using good solvents containing a high concentration $(300 \mathrm{mM})$ of LiBr decreased the drug loading. Approximately half of the TAM was adsorbed on the surface of the NPs (Figure 5A,B). Anti-solvent precipitation procedures reportedly occur in three steps. The first step is supersaturation of the solute. The second step is nucleation. The third is the growth of particles, which kinetically stops their aggregation, resulting in the formation of NPs $[34,42]$. Using a good solvent containing LiBr resulted in an incremental change in the apparent molecular weight of the unimer, up to 2.5 times in the case of $300 \mathrm{mM}$ LiBr (Figure 4 and Table S1). This led to the shortened duration of supersaturation of unimers and growth of NPs. However, the duration of TAM did not change, because the solubility of TAM in $10 \mathrm{v} / \mathrm{v} \% \mathrm{DMF}$ aqueous solution containing 0 to $30 \mathrm{mM} \mathrm{LiBr}$ at $65{ }^{\circ} \mathrm{C}$ did not change (data not shown; all investigated conditions were below the detection limit of TAM concentrations). Moreover, the $\mathrm{T}_{\mathrm{m}}$ of the stereocomplex domains was analyzed using lyophilization NPs. The addition of $300 \mathrm{mM}$ LiBr resulted in a significantly higher $\mathrm{T}_{\mathrm{m}}$ (Figure S4). This result also supports our hypothesis that a lower encapsulation TAM led to increased crystallinity of the core PLA domain. This is the reason why both DLC $_{\text {conv. }}$ and DLC $_{\text {SPE }}$ were lower in NPs prepared with $300 \mathrm{mM}$ LiBr. Approximately half of the TAM adsorbed on the surface of NPs was also supported by the release method (Figure S2B). Until $24 \mathrm{~h}$, surface-adsorbed TAM was released, followed by the release of encapsulated TAM from $48 \mathrm{~h}$ to $96 \mathrm{~h}$. Previous studies also reported that PLGA-PEG NP-loaded hydrophobic drugs showed bi-phasic release profiles. In this system, surface-adsorbed drugs were predominantly released, followed by a continuous slow release [43]. Our results agree with this release pattern.

\subsection{Different NP Preparation Conditions Altered PK Profiles and Biodistributions of SC-PEG NPS}

PK profiles and biodistributions were evaluated using two types of NPs prepared by




both ${ }^{111} \mathrm{In}$-SC-PEG NPs and ${ }^{14}$ C-TAM, and lower accumulations in the liver and spleen. These results suggest that higher PEG densities contribute to the reduction in distributions to these tissues due to the less exposed hydrophobic surface, which leads to the decreased clearance of NPs from blood. The $\mathrm{CL}_{\text {tot }}$ of NPs also supported this hypothesis. Previous studies also reported that PEG-dense NPs reduce the protein corona, which leads to recognition of the reticuloendothelial system (RES) and shortened duration of circulation $[7,44]$. Hydrodynamic diameters are also reportedly governed by specific surface area in the case of red blood cell membrane-coated NPs [41]. In contrast, the difference between $\mathrm{NP}_{\text {Sparse-Small }}$ and $\mathrm{NP}_{\text {Dense-Large }}$ was $61 \mathrm{~nm}$ and $105 \mathrm{~nm}$, respectively; it was also reported that this difference was not critical for RES recognition [7,45]. A size-dependency of distributions of NPs to RES was reported [41,46]. This discrepancy would be raised from two factors. One was the fenestra diameter of the mouse liver, which ranged up to $150 \mathrm{~nm}$ [47]. In the present study, our prepared NPs were smaller than this fenestra opening; thus, they would be passed through them and avoid RES recognition. The other is the formation of a protein corona, which interacts with the surface of the NPs [7,44]. Once the protein corona is formed, the RES recognized NPs [48]. Most reports were not distinguished from the interaction between $D_{h}$ and surface properties; thus, in our delivery systems, $\mathrm{NP}_{\text {Sparse-Small }}$ could form a protein corona due to their hydrophobic surface properties, leading to an increase in distribution to the liver and spleen where RES existed. Detailed investigations such as the preparation of $\mathrm{NP}_{\text {Dense-Small }}$ and $\mathrm{NP}_{\text {Sparse-Large }}$ using newly synthesized PLA-PEG unimers are required. However, in the present study, we focused on the interactions of preparation procedures, characteristics of NPs, and PK profiles using single SC-PEG $\mathrm{uni}_{\text {un }}$ to estimate the manufacture of SC-PEG NPs, which indicated that process parameters affected the characteristics of NPs and their PK profiles and biodistributions. Thus, surface PEG densities could be a potentially critical quality attribute in terms of changing biodistributions.

As mentioned above, TAM was adsorbed onto the surface of SC-PEG NPs. The surfaceadsorbed TAM was predominantly released upon intravenous injection. The $\mathrm{C}_{0}$ of TAM

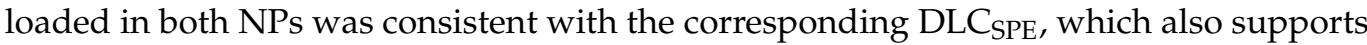
our hypothesis. Previous studies also reported that polymeric NPs could adsorb drugs on the surface of NPs and were immediately released in the physiological milieu $[49,50]$. Our results correspond to these previous reports.

\section{Conclusions}

In the present study, novel strategies to optimize the characteristics of SC-PEG NPs were investigated by changing the processing temperature, TFR, and using a good solvent containing ion excipients $(\mathrm{LiBr})$. The processing temperature affected $\mathrm{PdI}_{\mathrm{NP}}$ and surface PEG densities. Higher temperatures above the $T_{m}$ of PEG produced a sharper distribution and higher surface PEG densities of SC-PEG NPs. Using solvents containing LiBr increased the apparent molecular weight, which increased the size of the NPs. The combination of good solvents containing $\mathrm{LiBr}$ and altering the TFR could control the surface PEG densities by changing the $\mathrm{D}_{\mathrm{h}}$ of the SC-PEG NPs. However, a high concentration ( $\left.300 \mathrm{mM}\right)$ of LiBr caused a decrease in the DLC. The PK profiles and tissue distributions of the SC-PEG NPs were also altered by changing the processing conditions. SC-PEG NPs prepared using a solvent containing $100 \mathrm{mM} \mathrm{LiBr}$ and TFR of $3 \mathrm{~mL} / \mathrm{min}$ resulted in higher AUCs and lower tissue distributions compared to those prepared using a solvent containing $20 \mathrm{mM} \mathrm{LiBr}$ and TFR of $8 \mathrm{~mL} / \mathrm{min}$. To the best of our knowledge, this is the first report showing that the combination of changing processing temperature, TFR, and using a solvent containing ion excipients $(\mathrm{LiBr})$ is an effective strategy to regulate the characteristics of polymeric NPs. Processing parameters altered the PK profiles and tissue distributions. These findings should be helpful to make the manufacturing process of polymeric NPs robust and to control their critical quality attributes. 
Supplementary Materials: The following supporting information can be downloaded from https:// www.mdpi.com/article/10.3390/pharmaceutics14030568/s1, Figure S1: Size-exclusion chromatography-refractive index (SEC-RI) chromatogram and ${ }^{1 \mathrm{H}}$-NMR spectra of PLA-PEG unimers, Figure S2: Encapsulation efficiency (EE) and release profile of tamoxifen (TAM) from SC-PEG nanoparticles (NPs), Figure S3: Hydrodynamic diameters (Dh), polydispersity index (PdINP), surface PEG densities, and surface PEG contents of SC-PEG nanoparticles (NPs) prepared by different process conditions, Figure S4: Melting temperature (Tm) of PLA domain in lyophilized SC-PEG nanoparticles (NPs) prepared by different processing parameters and Table S1: Relative molecular weight and polydispersity of SC-PEG unimer in DMF containing LiBr.

Author Contributions: Conceptualization, K.O.; methodology, K.O. and H.K.; validation, K.O.; formal analysis, K.O.; investigation, K.O. and H.K.; resources, H.K., Y.M., M.M. and A.Y.; data curation, K.O.; writing—original draft preparation, K.O.; writing-review and editing, K.O., H.K., Y.M., M.M. and A.Y.; visualization, K.O.; supervision, H.K., Y.M. and A.Y.; project administration, H.K. and Y.M.; All authors have read and agreed to the published version of the manuscript.

Funding: This research received no external funding.

Institutional Review Board Statement: The animal study protocol was approved by the Animal Experimentation Committee of Kyoto Pharmaceutical University (protocol code 17-029, date of approval April 2017).

Data Availability Statement: Data are contained within the article or Supplementary Material. The data presented in this study are available in inset articles or the Supplementary Material here.

Acknowledgments: We thank Daiki Nomura and Yoshie Niwa of Shionogi Co., Ltd. for their technical support and advice.

Conflicts of Interest: The employees Kohei Ogawa and Yasushi Moroto are employed at Shionogi \& Co. Kohei Ogawa and Yasushi Moroto have no economical or commercial interest to disclaim. The other authors declare no conflict of interest.

\section{References}

1. Chawla, S.P.; Goel, S.; Chow, W.; Braiteh, F.; Singh, A.S.; Grilley Olson, J.E.; Osada, A.; Bobe, I.; Riedel, R.F. A Phase 1b Dose Escalation Trial of NC-6300 (Nanoparticle Epirubicin) in Patients with Advanced Solid Tumors or Advanced, Metastatic, or Unresectable Soft-tissue Sarcoma. Clin. Cancer Res. 2020, 26, 4225-4232. [CrossRef] [PubMed]

2. Harada, M.; Bobe, I.; Saito, H.; Shibata, N.; Tanaka, R.; Hayashi, T.; Kato, Y. Improved anti-tumor activity of stabilized anthracycline polymeric micelle formulation, NC-6300. Cancer Sci. 2011, 102, 192-199. [CrossRef] [PubMed]

3. Autio, K.A.; Dreicer, R.; Anderson, J.; Garcia, J.A.; Alva, A.; Hart, L.L.; Milowsky, M.I.; Posadas, E.M.; Ryan, C.J.; Graf, R.P.; et al. Safety and Efficacy of BIND-014, a Docetaxel Nanoparticle Targeting Prostate-Specific Membrane Antigen for Patients with Metastatic Castration-Resistant Prostate Cancer: A Phase 2 Clinical Trial. JAMA Oncol. 2018, 4, 1344-1351. [CrossRef]

4. Von Hoff, D.D.; Mita, M.M.; Ramanathan, R.K.; Weiss, G.J.; Mita, A.C.; Lorusso, P.M.; Burris, H.A.; Hart, L.L.; Low, S.C.; Parsons, D.M.; et al. Phase I study of PSMA-targeted docetaxel-containing nanoparticle BIND-014 in patients with advanced solid tumors. Clin. Cancer Res. 2016, 22, 3157-3163. [CrossRef] [PubMed]

5. Houdaihed, L.; Evans, J.C.; Allen, C. In vivo evaluation of dual-targeted nanoparticles encapsulating paclitaxel and everolimus. Cancers 2019, 11, 752. [CrossRef]

6. Rabanel, J.M.; Faivre, J.; Tehrani, S.F.; Lalloz, A.; Hildgen, P.; Banquy, X. Effect of the polymer architecture on the structural and biophysical properties of PEG-PLA nanoparticles. ACS Appl. Mater. Interfaces 2015, 7, 10374-10385. [CrossRef]

7. Bertrand, N.; Grenier, P.; Mahmoudi, M.; Lima, E.M.; Appel, E.A.; Dormont, F.; Lim, J.M.; Karnik, R.; Langer, R.; Farokhzad, O.C. Mechanistic understanding of in vivo protein corona formation on polymeric nanoparticles and impact on pharmacokinetics. Nat. Commun. 2017, 8, 777. [CrossRef]

8. Afsharzadeh, M.; Abnous, K.; Yazdian-Robati, R.; Ataranzadeh, A.; Ramezani, M.; Hashemi, M. Formulation and evaluation of anticancer and antiangiogenesis efficiency of PLA-PEG nanoparticles loaded with galbanic acid in C26 colon carcinoma, in vitro and in vivo. J. Cell. Physiol. 2019, 234, 6099-6107. [CrossRef]

9. Sim, T.; Kim, J.E.; Hoang, N.H.; Kang, J.K.; Lim, C.; Kim, D.S.; Lee, E.S.; Youn, Y.S.; Choi, H.G.; Han, H.K.; et al. Development of a docetaxel micellar formulation using poly(Ethylene glycol)-polylactide-poly(ethylene glycol, PEG-PLA-PEG) with successful reconstitution for tumor targeted drug delivery. Drug Deliv. 2018, 25, 1371-1380. [CrossRef]

10. Bertranda, N.; Wu, J.; Xu, X.; Kamaly, N.; Farokhzad, O.C. Cancer nanotechnology: The impact of passive and active targeting in the era of modern cancer biology. Adv. Drug Deliv. Rev. 2014, 66, 2-25. [CrossRef] 
11. Kyzioł, A.; Kyzioł, K. Surface Functionalization with Biopolymers via Plasma-Assisted Surface Grafting and Plasma-Induced Graft Polymerization-Materials for Biomedical Applications, Biopolymer Grafting, 1st ed.; Thakur, V.K., Ed.; Elsevier: Amsterdam, The Netherlands, 2018; pp. 115-151. [CrossRef]

12. Ogawa, K.; Katsumi, H.; Takata, K.; Nomura, D.; Moroto, Y.; Kitamura, H.; Takaki, C.; Morishita, M.; Yamamoto, A. Orthogonal Characterization and Pharmacokinetic Studies of Polylactide-Polyethyleneglycol Polymeric Nanoparticles with Different Physicochemical Properties. Int. J. Pharm. 2021, 608, 121120. [CrossRef]

13. European Medicines Agency and Ministry of Health, Labour and Welfare. Joint MHLW/EMA Reflection Paper on the Development of Block Copolymer Micelle Medicinal Products. 2013. Available online: https://www.ema.europa.eu/en/ documents / scientific-guideline/draft-joint-ministry-health-labour-welfare/european-medicines-agency-reflection-paperdevelopment-block-copolymer-micelle-medicinal-products_en.pdf (accessed on 7 February 2022).

14. US Department of Health and Human Services, Food and Drug Administration. Guidance for Industry, Drug Products, Including Biological Products, That Contain Nanomaterials. 2017. Available online: https://www.fda.gov/media/109910/download (accessed on 7. February 2022).

15. Bresseleers, J.; Bagheri, M.; Lebleu, C.; Lecommandoux, S.; Sandre, O.; Pijpers, I.A.B.; Mason, A.F.; Meeuwissen, S.; van Nostrum, C.F.; Hennink, W.E.; et al. Tuning size and morphology of mpeg-b-p(Hpma-bz) copolymer self-assemblies using microfluidics. Polymers 2020, 12, 2572. [CrossRef]

16. O'Reilly Beringhs, A.; Ndaya, D.; Bosire, R.; Kasi, R.M.; Lu, X. Stabilization and X-ray Attenuation of PEGylated Cholesterol/Polycaprolactone-Based Perfluorooctyl Bromide Nanocapsules for CT Imaging. AAPS PharmSciTech 2021, 22, 90. [CrossRef] [PubMed]

17. Troiano, G.; Nolan, J.; Parsons, D.; Van Geen Hoven, C.; Zale, S. A Quality by Design Approach to Developing and Manufacturing Polymeric Nanoparticle Drug Products. AAPS J. 2016, 18, 1354-1365. [CrossRef]

18. Duanmu, Y.; Riche, C.T.; Gupta, M.; Malmstadt, N.; Huang, Q. Scale-up modeling for manufacturing nanoparticles using microfluidic T-junction. IISE Trans. 2018, 50, 892-899. [CrossRef]

19. Jeffs, L.B.; Palmer, L.R.; Ambegia, E.G.; Giesbrecht, C.; Ewanick, S.; MacLachlan, I. A scalable, extrusion-free method for efficient liposomal encapsulation of plasmid DNA. Pharm. Res. 2005, 22, 362-372. [CrossRef] [PubMed]

20. Riewe, J.; Erfle, P.; Melzig, S.; Kwade, A.; Dietzel, A.; Bunjes, H. Antisolvent precipitation of lipid nanoparticles in microfluidic systems-A comparative study. Int. J. Pharm. 2020, 579, 119167. [CrossRef]

21. Kulkarni, J.A.; Tam, Y.Y.C.; Chen, S.; Tam, Y.K.; Zaifman, J.; Cullis, P.R.; Biswas, S. Rapid synthesis of lipid nanoparticles containing hydrophobic inorganic nanoparticles. Nanoscale 2017, 9, 13600-13609. [CrossRef] [PubMed]

22. Matteucci, M.E.; Hotze, M.A.; Johnston, K.P.; Williams, R.O. Drug nanoparticles by antisolvent precipitation: Mixing energy versus surfactant stabilization. Langmuir 2006, 22, 8951-8959. [CrossRef]

23. Mori, S. Calibration of Size Exclusion Chromatography Columns for Molecular Weight Determination of Poly(acrylonitrile) and Poly(vinylpyrrolidone) in N,N-Dimethylformamide. Anal. Chem. 1983, 55, 2414-2416. [CrossRef]

24. Krishnan, P.S.G.; Veeramani, S.; Vora, R.H.; Chung, T.S.; Uchimura, S.I.; Sugitani, H. Molecular mass determination of polyamic acid ionic salt by size-exclusion chromatography. J. Chromatogr. A 2002, 977, 207-212. [CrossRef]

25. Takata, K.; Kawahara, K.; Yoshida, Y.; Kuzuya, A.; Ohya, Y. Analysis of the sol-to-gel transition behavior of temperature-responsive injectable polymer systems by fluorescence resonance energy transfer. Polym. J. 2017, 49, 677-684. [CrossRef]

26. Ma, C.; Pan, P.; Shan, G.; Bao, Y.; Fujita, M.; Maeda, M. Core-Shell structure, biodegradation, and drug release behavior of poly(lactic acid)/poly(ethylene glycol) block copolymer micelles tuned by macromolecular stereostructure. Langmuir 2015, 31, 1527-1536. [CrossRef]

27. Ghasemi, R.; Abdollahi, M.; Emamgholi Zadeh, E.; Khodabakhshi, K.; Badeli, A.; Bagheri, H.; Hosseinkhani, S. MPEG-PLA and PLA-PEG-PLA nanoparticles as new carriers for delivery of recombinant human Growth Hormone (rhGH). Sci. Rep. 2018, 8, 9854. [CrossRef] [PubMed]

28. Matsuura, S.; Katsumi, H.; Suzuki, H.; Hirai, N.; Hayashi, H.; Koshino, K.; Higuchi, T.; Yagi, Y.; Kimura, H.; Sakane, T.; et al L-Serine-modified polyamidoamine dendrimer as a highly potent renal targeting drug carrier. Proc. Natl. Acad. Sci. USA 2018, 115, 10511-10516. [CrossRef]

29. Yamashita, S.; Katsumi, H.; Hibino, N.; Isobe, Y.; Yagi, Y.; Tanaka, Y.; Yamada, S.; Naito, C.; Yamamoto, A. Development of PEGylated aspartic acid-modified liposome as a bone-targeting carrier for the delivery of paclitaxel and treatment of bone metastasis. Biomaterials 2018, 154, 74-85. [CrossRef]

30. Yamaoka, K.; Tanigawara, Y.; Nakagawa, T.; Uno, T. A pharmacokinetic analysis program (MULTI) for microcomputer. J. Pharm. Dyn. 1981, 4, 879-885. Available online: http://www.mendeley.com/research/geology-volcanic-history-eruptive-styleyakedake-volcano-group-central-japan/ (accessed on 7. February 2022.). [CrossRef]

31. Zhu, L.; Cheng, S.Z.D.; Calhoun, B.H.; Ge, Q.; Quirk, R.P.; Thomas, E.L.; Hsiao, B.S.; Yeh, F.; Lotz, B. Crystallization temperaturedependent crystal orientations within nanoscale confined lamellae of a self-assembled crystalline-Amorphous diblock copolymer. J. Am. Chem. Soc. 2000, 122, 5957-5967. [CrossRef]

32. Hamley, I.W.; Fairclough, J.P.A.; Terrill, N.J.; Ryan, A.J.; Lipic, P.M.; Bates, F.S.; Towns-Andrews, E. Crystallization in oriented semicrystalline diblock copolymers. Macromolecules 1996, 29, 8835-8843. [CrossRef] 
33. Diou, O.; Greco, S.; Beltran, T.; Lairez, D.; Authelin, J.R.; Bazile, D. A method to Quantify the Affinity of Cabazitaxel for PLA-PEG Nanoparticles and Investigate the Influence of the Nano-Assembly Structure on the Drug/Particle Association. Pharm. Res. 2015, 32, 3188-3200. [CrossRef]

34. Karnik, R.; Gu, F.; Basto, P.; Cannizzaro, C.; Dean, L.; Kyei-Manu, W.; Langer, R.; Farokhzad, O.C. Microfluidic platform for controlled synthesis of polymeric nanoparticles. Nano Lett. 2008, 8, 2906-2912. [CrossRef] [PubMed]

35. Hann, N.D. Effects of lithium bromide on the gel-permeation chromatography of polyester-based polyurethanes in dimethylformamide. J. Polym. Sci. Part A Gen. Pap. 1977, 15, 1331-1339. [CrossRef]

36. Idris, A.; Ahmed, I. Viscosity behavior of microwave-heated and conventionally heated poly(ether sulfone)/dimethylformamide/ lithium bromide polymer solutions. J. Appl. Polym. Sci. 2008, 108, 302-307. [CrossRef]

37. Zhao, W.; Simmons, B.; Singh, S.; Ragauskas, A.; Cheng, G. From lignin association to nano-/micro-particle preparation: Extracting higher value of lignin. Green Chem. 2016, 18, 5693-5700. [CrossRef]

38. Lim, J.M.; Swami, A.; Gilson, L.M.; Chopra, S.; Choi, S.; Wu, J.; Langer, R.; Karnik, R.; Farokhzad, O.C. Ultra-high throughput synthesis of nanoparticles with homogeneous size distribution using a coaxial turbulent jet mixer. ACS Nano 2014, 8, 6056-6065. [CrossRef]

39. Kim, Y.; Lee Chung, B.; Ma, M.; Mulder, W.J.M.; Fayad, Z.A.; Farokhzad, O.C.; Langer, R. Mass production and size control of lipid-polymer hybrid nanoparticles through controlled microvortices. Nano Lett. 2012, 12, 3587-3591. [CrossRef]

40. Abstiens, K.; Goepferich, A.M. Microfluidic manufacturing improves polydispersity of multicomponent polymeric nanoparticles J. Drug Deliv. Sci. Technol. 2019, 49, 433-439. [CrossRef]

41. Li, H.; Jin, K.; Luo, M.; Wang, X.; Zhu, X.; Liu, X.; Jiang, T.; Zhang, Q.; Wang, S.; Pang, Z. Size Dependency of Circulation and Biodistribution of Biomimetic Nanoparticles: Red Blood Cell Membrane-Coated Nanoparticles. Cells 2019, 8, 881. [CrossRef]

42. Martínez Rivas, C.J.; Tarhini, M.; Badri, W.; Miladi, K.; Greige-Gerges, H.; Nazari, Q.A.; Galindo Rodríguez, S.A.; Román, R.Á.; Fessi, H.; Elaissari, A. Nanoprecipitation process: From encapsulation to drug delivery. Int. J. Pharm. 2017, 532, 66-81. [CrossRef]

43. Esnaashari, S.S.; Amani, A. Optimization of Noscapine-Loaded mPEG-PLGA Nanoparticles and Release Study: A Response Surface Methodology Approach. J. Pharm. Innov. 2018, 13, 237-246. [CrossRef]

44. Zhou, H.; Fan, Z.; Li, P.Y.; Deng, J.; Arhontoulis, D.C.; Li, C.Y.; Bowne, W.B.; Cheng, H. Dense and Dynamic Polyethylene Glycol Shells Cloak Nanoparticles from Uptake by Liver Endothelial Cells for Long Blood Circulation. ACS Nano 2018, 12, 10130-10141. [CrossRef] [PubMed]

45. Mirkasymov, A.B.; Zelepukin, I.V.; Nikitin, P.I.; Nikitin, M.P.; Deyev, S.M. In vivo blockade of mononuclear phagocyte system with solid nanoparticles: Efficiency and affecting factors. J. Control. Release 2021, 330, 111-118. [CrossRef] [PubMed]

46. Caster, J.M.; Yu, S.K.; Patel, A.N.; Newman, N.J.; Lee, Z.J.; Warner, S.B.; Wagner, K.T.; Roche, K.C.; Tian, X.; Min, Y.; et al. Effect of particle size on the biodistribution, toxicity, and efficacy of drug-loaded polymeric nanoparticles in chemoradiotherapy. Nanomed. Nanotechnol. Biol. Med. 2017, 13, 1673-1683. [CrossRef] [PubMed]

47. Gaumet, M.; Vargas, A.; Gurny, R.; Delie, F. Nanoparticles for drug delivery: The need for precision in reporting particle size parameters. Eur. J. Pharm. Biopharm. 2008, 69, 1-9. [CrossRef]

48. Wang, J.-L.; Du, X.-J.; Yang, J.-X.; Shen, S.; Li, H.-J.; Luo, Y.-L.; Iqbal, S.; Xu, C.-F.; Ye, X.-D.; Cao, J.; et al. The effect of surface poly(ethylene glycol) length on in vivo drug delivery behaviors of polymeric nanoparticles. Biomaterials 2018, 182, 104-113. [CrossRef]

49. Yang, H.; Yuan, B.; Zhang, X.; Scherman, O.A. Supramolecular chemistry at interfaces: Host-guest interactions for fabricating multifunctional biointerfaces. Acc. Chem. Res. 2014, 47, 2106-2115. [CrossRef]

50. Crucho, C.I.C.; Barros, M.T. Polymeric nanoparticles: A study on the preparation variables and characterization methods. Mater Sci. Eng. C 2017, 80, 771-784. [CrossRef] 